\title{
Management of severe Falciparum malaria on a mission: A case report
}

\author{
Manuel Monti \\ Emergency Department, Local Health Unit “Umbria 1", Assisi, Italy
}

\begin{abstract}
A sailor for forty-two years, in military service on the Italian aircraft carrier, while on a mission in sub-Saharan Africa, came to a physician due to fatigue with a fever, flu-like illness and headache for 6 days. The temperature was $38.8^{\circ} \mathrm{C}$, BP $80 / 145 \mathrm{mmHg}$ and $\mathrm{RR}$ $30 /$ min. The oxygen saturation was $88 \%$, while the patient was breathing room air. Laboratory findings showed that WBC count and platelet counts were greatly reduced. Blood smears were positive for Plasmodium falciparum malaria with more than 10 parasites per field. It began immediately antimalarial treatment. After 24 hours the patient showed a $50 \%$ reduction in parasitemia but continued to have tachypnoea, dyspnea and hypoxemia. A chest TC scan was then performed that revealed a right basal alveolar consolidation with bilateral pleural effusion. The patient was ultimately diagnosed with pneumonia and malaria (overlap syndrome). The patient began antibiotic and steroid therapy. After two days the fever was gone away and the clinical condition of the patient was greatly improved. The clinical overlap between pneumonia and malaria has important implications for case management strategies and their treatment should be integrated into community case management activities.
\end{abstract}

\section{Introduction}

Malaria is an infectious disease caused by the protozoan of the genus Plasmodium [1]. Five Plasmodium species ( $P$. falciparum, $P$. vivax, $P$. malaria, $P$. ovale, and $P$. knowlesi) are responsible for almost all human cases of malaria [2].

Correspondence: Manuel Monti, USL Umbria1 U.O. PS/118, Via V. Muller 1, 06081 Assisi (PG), Italy.

E-mail: montimanuel@tiscali.it

Key words: Malaria; Plasmodium falciparum; acute respiratory failure; military personnel.

Received for publication: 11 May 2018.

Accepted for publication: 26 December 2018.

(C) Copyright M. Monti, 2019

Licensee PAGEPress, Italy

Monaldi Archives for Chest Disease 2019; 89:963

doi: 10.4081/monaldi.2019.963

This article is distributed under the terms of the Creative Commons Attribution Noncommercial License (by-nc 4.0) which permits any noncommercial use, distribution, and reproduction in any medium, provided the original author(s) and source are credited.
It is a major problem in sub-Saharan Africa countries, with hundreds of millions of infections and millions of casualties per year. Without treatment in the nonimmune patient, falciparum malaria can progress to severe disease in days, characterized by multiorgan dysfunction and a mortality of up to $20 \%$ to $35 \%$, even with adequate antimalarial treatment [3].

For centuries, malaria has been considered a significant threat to the health and effectiveness of military forces that conduct operations in malaria-endemic areas. Military personnel continue to be deployed to malaria risk areas for prolonged periods of time $[4,5]$. The main contagion factor is poor compliance with chemoprophylaxis between military personnel both during and after decompositions, sometimes related to common side effects [7].

However, adherence to protective measures of medical forces can be improved through the education and simplification of chemoprophylaxis regimes.

\section{Case Report}

A 42-year-old man, unmarried office worker and non-smoker, was admitted in 2015, in Role 2 of Navy, with a fever, headache, flu-like illness, cough, shortness of breath and myalgia.

The temperature was $38.8^{\circ} \mathrm{C}$, the blood pressure was $80 / 145$ $\mathrm{mmHg}$, respiratory rate (RR) of 30 breaths/min and the oxygen saturation was $88 \%$. The patient had normal heart and breath sounds. Abdomen, neurological and musculoskeletal examinations were unremarkable. In history, the patient reported no antimalarial prophylaxis.

Laboratory tests have shown white blood cell count $1.9 \mathrm{x}$ $103 / \mathrm{mm}^{3}$ and platelet count $78 \times 103 / \mathrm{mm}^{3}$ Prothrombin and activated partial tissue thromboplastin times were normal (Table 1). The serum hepatitis B virus (HBV) surface antigen, hepatitis C virus (HCV) antibody, hepatitis A virus (HAV) IgM antibody, and human immunodeficiency virus (HIV) antibody, were all negative.

An ABG (arterial blood gas), with the patient breathing spontaneously, revealed $(\mathrm{ABG}) \mathrm{pH}$ of $7.36, \mathrm{PaCO} 2$ at $25.6 \mathrm{mmHg}$, $\mathrm{PaO} 2$ at $87.4 \mathrm{mmHg}$, bicarbonate at $21.2 \mathrm{mmol} / \mathrm{L}$, and lactate at $1.8 \mathrm{mmol} / \mathrm{L}$.

A blood smear detected a Plasmodium falciparum, with more than 10 parasites per field. Film and stained it for malaria parasite identification using GIEMSA staining methods. The diagnosis was confirmed using the rapid diagnosis specifically for $P$. falciparum. A urine sample was taken to exclude other infections.

Among the criteria of diagnosis of severe malaria, the patient presented only hyperparasitemia ( $P$. falciparum parasitemia $>10 \%$ ) and, for this reason, oral therapy was preferred [7].

The patient, who was already treated with crystalloids and paracetamol for the hyperpyretic syndrome, was immediately subjected with Atovaquone / Proguanil (250 mg / $100 \mathrm{mg}) 4$ tablets once a day for 3 days. Hematochemical examinations showed the 
persistence of thrombocytopenia $\left(40.000 \mathrm{~mm}^{3}\right)$ and progressive improvement of leukocyte $\left(6.800 \mathrm{~mm}^{3}\right)$. Twenty-four h after starting therapy, a second blood smear showed that the parasitemia was reduced by half, but the patient continued having dry cough, tachypnea, dyspnea, and hypoxemia ( $82 \%)$, as assessed by oxygen desaturation on pulse oximetry. Oxygen (Venturi mask 40\%) was delivered to the patient, and a chest X-ray and computed tomography of the lungs were performed. A CT scan of the chest showed bilateral pleural effusion, airspace shadowing (consolidation) and ground-glass appearance involving both lungs.

The findings were suggestive of interstitial pneumonia with acute respiratory distress syndrome. He was commenced on highdose prednisolone. The steroids were continued and the patient started antibiotic therapy (with piperacillin $4 \mathrm{~g} /$ tazobactam 500 $\mathrm{mg}, 3$ times a day). His condition improved on supportive treatment, and he was discharged home after 10 days.

\section{Discussion}

Vector-borne and environmentally-acquired infections are a threat to all travelers to endemic locations, but military personnel are at elevated risk due to the duration and intensity of environmental exposure. When evaluating fever in military personnel, a careful history should include country and terrain of any deployments [8].

The case of malaria described here was acquired in West Africa, probably in the ports of Lwanda (Angola) and Pointe Noire (Congo), previously visited by the Italian Naval Unit.

Malaria should be considered in all travelers from endemic areas presenting with fever, especially if they have thrombocytopenia and anemia. Classical presentation, consisting of paroxysms of fever alternating with periods of fatigue but otherwise relative wellness, can be observed in only $50-70 \%$ of the cases. The associated symptoms include sweats, myalgia, abdominal pain and intestinal symptoms [9]. According to the WHO criteria impaired consciousness, prostration, respiratory distress, multiple seizures,

Table 1. Patient's main serum chemistry values.

\begin{tabular}{lcc} 
Laboratory data & Numerical value & Normal range values \\
$\mathrm{Hb}$ & 14.0 & $13.5-17 \mathrm{gr} / \mathrm{dl}$ \\
$\mathrm{MCV}$ & 82.2 & $75-98 \mathrm{fl}$ \\
\hline $\mathrm{MCHC}$ & 35.8 & $31-38 \mathrm{gr} / \mathrm{dl}$ \\
Hematocrit & 34.3 & $15.9-44.1 \%$ \\
\hline PLT & $78 \times 10^{3}$ & $140-440 \times 10^{3} \mathrm{~mm}^{3}$ \\
WBC & $1.9 \times 10^{3}$ & $3.5-10 \times 10^{3} \mathrm{~mm}^{3}$ \\
\hline Aspartate transaminase & 488 & $10-40 \mathrm{UI} / \mathrm{L}$ \\
Alanine transaminase & 573 & $10-40 \mathrm{UI} / \mathrm{L}$ \\
\hline Sodium & 135 & $136-145 \mathrm{mmol} / \mathrm{L}$ \\
Potassium & 4.3 & $3.5-5.1 \mathrm{mmol} / \mathrm{L}$ \\
\hline Bilirubin total & 0.9 & $0.2-1.1 \mathrm{mg} / \mathrm{dl}$ \\
Protein total & 7.4 & $6.48 .3 \mathrm{mg} / \mathrm{dl}$ \\
\hline Albumin & 3.6 & $3.8-5.1 \mathrm{mg} / \mathrm{dl}$ \\
Creatinine & 0.9 & $0.8-1.2 \mathrm{mg} / \mathrm{dl}$ \\
\hline
\end{tabular}

$\mathrm{Hb}$, hemoglobin; MCV, mean corpuscular volume; $\mathrm{MCHC}$, mean corpuscular hemoglobin concentration; PLT, platelets; WBC, white blood cells; LDH, lactate dehydrogenase. jaundice, hemoglobinuria, abnormal bleeding, severe anemia, circulatory collapse and pulmonary edema are features of severe malaria [7].

Uncommon presentations more frequent in P. Falciparum malaria are acute abdomen or intestinal obstruction, viral hepatitislike illness, Guillain-Barré syndrome, severe headache, hemiplegia, pancytopenia, cardiac and respiratory disorders. Several pulmonary syndromes in severe malaria have been described, such as acute non-cardiogenic pulmonary edema ARDS, acute pulmonary injury and interstitial pneumonia. In particular, it has been shown that impaired lung function depends on small obstruction sense of air, gas exchange abnormalities, and an increase in pulmonary phagocytic. This is due to the accumulation of monocytes and a pulmonary intravascular inflammatory response $[10,11]$.

Severe pulmonary complications of malaria usually appear from six hours to eight days after the initiation of anti-malarial treatment. These findings are consistent with what is observed in cases of falciparum malaria, and they could correspond to an exacerbation of the post-treatment inflammatory response. Nevertheless, our patient presented severe pulmonary symptoms before the initiation of antimalarial treatment, characterized as pneumonia [12]. The clinical overlap between pneumonia and malaria has important implications for proper patient management. Studies conducted in different countries indicate that there is a significant overlap in the clinical presentation of pneumonia and malaria [13]. Case management algorithms are based on the premise that a patient is likely to have only one disease at a time. On the other hand, a patient can have both diseases but must be evaluated and treated for only one disease. For this reason, in the management of patients with pulmonary complications, it is important carefully evaluating the pulmonary symptoms and the results of the investigation and deciding, in case of doubt, to initiate a dual therapy.

\section{Conclusions}

Military populations continue to be at a high risk of malaria and reported case series have frequently revealed poor compliance with preventative measures. The symptoms of malaria are non-specific and its management depends on awareness of the diagnosis and early recognition and treatment.

In particular, pulmonary complications of malaria can be misdiagnosed as acute respiratory illnesses. This has been noted to be more prevalent in the background of national or international emerging diseases. The early recognition and effective intensive care support can greatly reduce mortality and improve outcomes.

\section{References}

1. Wilson ME, Weid LH, Boggild A, et al. Fever in returned travelers: results from the Geo. Sentinel Surveillance Network. Clin Infect Dis 2007; 44:1560-8.

2. Leder K, Black J, O'Brien D, et al. Malaria in travelers: a review of the GeoSentinel surveillance network. Clin Infect Dis 2004;39:1104-12.

3. Mace KE, Arguin PM. Malaria Surveillance - United States, 2014. MMWR Surveill Summ 2017;66:1-24.

4. Kotwal RS, Wenzel RB, Sterling RA, et al. Outbreak of malaria in US army rangers returning from Afghanistan. JAMA 2005;293:212-16. 
5. Tuck JJ, Green AD, Roberts KI. A malaria outbreak following a British military deployment to Sierra Leone. J Infect 2003; 47:225-30.

6. Murphy D, Strong A. Investigating factors associated with reporting concerns towards malaria prophylaxis, and the content of concerns amongst UK Service Personnel deployed to the Iraq conflict between 2003-2006: a mixed methods study. J R Army Med Corps 2010;156:28-31.

7. WHO. Guidelines for the Treatment of Malaria. World Health Organization; Geneva; 2015. Available from: https://www. ncbi.nlm.nih.gov/books/NBK294440/

8. Freedman DO, Weld LH, Kozarsky PE, et al. Spectrum of disease and relation to place of exposure among ill returned travelers. N Engl J Med 2006;354:119-30.

9. Zhong D, Lo E, Wang X, Yewhalaw D, et al. Multiplicity and molecular epidemiology of Plasmodium vivax and
Plasmodium falciparum infections in East Africa. Malar J 2018; $17: 185$.

10. Anstey NM, Jacups SP, Cain T, et al. Pulmonary manifestations of uncomplicated falciparum and vivax malaria: caught, small airways obstruction, impaired gas transfer, and increased pulmonary phagocytic activity. J Infect Dis 2002;185:1326-34.

11. Lomar AV, Vidal JE, Lomar FP, et al. Acute respiratory distress syndrome due to vivax malaria: case report and literature review. Braz J Infect Dis 2005;9:425-30.

12. Ukwaja KN, Aina OB, Talabi AA. Clinical overlap between malaria and pneumonia: can malaria rapid diagnostic test play a role? J Infect Dev Ctries 2011;5:199-203.

13. Akpede GO, Sykes RM. Malaria with bactraeimia in acutely febrile preschool children without localizing signs, coincidence or association/complication? J Trop Med Hyg 1993;96: 146-50. 